УДК 316.624 .3

DOI: $10.35750 / 2071-8284-2020-2-X X-215-222$

\author{
М. С. Недилько \\ адъюнкт \\ Санкт-Петербургский университет МВД России \\ Российская Федерачия, 198206, Санкт-Петербург, ул. Лётчика Пилютова, д. 1 \\ ORCID: 0000-0001-9884-7127. E-mail: samazha@mail.ru \\ К. В. Злоказов \\ кандидат психологических наук, доцент \\ Санкт-Петербургский университет МВД России \\ Российская Федерация, 198206, Санкт-Петербург, ул. Лётчика Пилютова, д. 1 \\ ORCID: 0000-0002-0664-8444. E-mail: zkirvit@rambler.ru

\section{Различия в субъективных представлениях бывших сотрудников правоохранительных органов, осуждённых за совершение корыстных и коррупционных преступлений}

\begin{abstract}
Аннотация: В статье обсуждаются теоретические основания исследования представлений у лиц, совершивших корыстные преступления. Описана роль представлений в регуляции социального поведения, приведены теоретические сведения и факты, раскрывающие роль представлений в регуляции преступного поведения. Обобщены мнения о специфике представлений у лиц, совершивших корыстные и коррупционные преступления. Рассматриваются положения концепций «осознанного поведения» и «криминального мышления» применительно к оценке представлений преступников. Описаны три вида представлений, присущих преступникам корыстного типа.

Определяются гипотезы эмпирического исследования представлений, описывается его процедура, методология и применяемые методы. Выборка составляет 211 бывших сотрудников правоохранительных органов, осуждённых за совершение корыстных и коррупционных преступлений. Методом исследования выступает специально разработанная анкета. Основные результаты приводятся с учётом статистической оценки различий в представлении о безнаказанности, обесценивании жертв и гедонистических установках.

Полученные результаты подтверждают гипотезу о различиях в представлениях между сопоставляемыми группами, а также о различиях во взаимосвязях данных представлений в группах сотрудников, совершивших преступления в период службы и после увольнения. Предполагается, что измеренные представления влияют на принятие решения о совершении корыстного преступления, стимулируя убеждение в безнаказанности, допустимости в отношении жертвы. Делается вывод о перспективности исследования представлений как показателя риска корыстных преступлений.
\end{abstract}

Ключевые слова: регуляция социального поведения, представления преступников, криминальное мышление безнаказанность, корыстные преступления, коррупция.

Для цитирования: Недилько М. С., Злоказов К. В. Различия в субъективных представлениях бывших сотрудников правоохранительных органов, осуждённых за совершение корыстных и коррупционных преступлений // Вестник Санкт-Петербургского университета МВД России. - 2020. № 2 (86). - C. 215-222. DOI: 10.35750/2071-8284-2020-2-215-222.

Maria S. Nedilko

Graduate

Saint-Petersburg University of the MIA of Russia

1, Letchika Pilyutova str., Saint-Petersburg, 198206, Russian Federation

ORCID: 0000-0001-9884-7127.E-mail: samazha@mail.ru 


\author{
Kirill V. Zlokazov \\ Cand. Sci. (Psy.), Docent \\ Saint-Petersburg University of the MIA of Russia \\ 1, Letchika Pilyutova str., Saint-Petersburg, 198206, Russian Federation \\ ORCID: 0000-0002-0664-8444. E-mail: zkirvit@rambler.ru
}

\title{
Differences in subjective representations of former law enforcement officers, convicted of lucrative crime and corruption
}

Annotation: The article discusses theoretical basis for study of representations of persons who have committed lucrative crimes. The role of representations in regulation of social behavior is described, theoretical information and facts confirming the role of representations in regulation of criminal behavior are given. Opinions are generalised as to the specifics of the perceptions of persons who have committed mercenary crimes and corruption. Theories of «planned behavior» and «criminal thinking» in relation to the assessment of criminal perceptions are discussed.

Hypotheses of empirical study of representations are defined, its procedure, methodology and methods applied are described. The sample of the survey comprises 211 former law enforcement officers convicted of lucrative and corruption crimes. The results are given taking into account the statistical assessment of differences in perceptions of impunity, victim depreciation and hedonistic attitudes.

The results support the hypothesis that there are differences in perceptions between the groups to be compared, as well as differences in the relationship of these perceptions among former law enforcement officers. It is assumed that the measured perceptions influence the decision to commit a lucrative crime by encouraging a belief in impunity and victim acceptance. The conclusion is that it is promising to study perceptions as an indicator of the risk of acquisitive crime.

Keywords: regulation of social behavior, perceptions of criminals, criminal thinking, impunity, mercenary crimes, corruption.

For citation: Nedilko M.S., Zlokazov K.V. Differences in the subjective representations of former law enforcement officers convicted of committing mercenary and corruption crimes // Vestnik of St. Petersburg University of the Ministry of Internal Affairs of Russia. - 2020. - № 2. - P. 215-222. DOI: 10.35750/20718284-2020-2-215-222.

\section{Введение}

Актуальность исследования обусловлена социальной значимостью противодействия коррупции и преступлениям, совершенным по мотиву корысти. Важное значение данная тематика имеет в отношении государственных служащих, чей социальный статус и возможности требуют наличия особой, сознательной позиции, а совершаемые преступления наносят не только материальный, но и репутационный ущерб. Научная значимость исследования определяется необходимостью развития знаний о психологических механизмах личности, регулирующих социальное поведение, в том числе совершение преступных действий.

Цель статьи - обобщение теоретических положений о представлениях личности как регуляторе противоправных действий, изучение ряда специфических представлений о престу- плении и жертве у сотрудников, осуждённых за совершение преступлений в период прохождения службы в правоохранительных органах.

В статье представлены результаты эмпирического исследования представлений о социальном поведении у представительной выборки бывших сотрудников правоохранительных органов, осужденных за совершение корыстных и коррупционных преступлений.

\section{Теоретические основания исследования}

В основу представленного исследования положена концепция регуляции личностью социального поведения, приводящая к преступному, а не правопослушному поведению. Она не связана с детерминационными теориями преступного поведения, занимающими главенствующую роль в криминальной психологии [1]. 
Концепция регуляции социального поведения предполагает, что человек имеет возможность выбора правового или преступного поведения, но осознанно и внутренне обоснованно предпочитает преступное. Соответственно, преступник понимает и оценивает данные действия и их последствия, но в силу собственных представлений всё же совершает преступление. Таким образом, среди существующих психологических теорий криминального поведения концепция носит дополняющий, а не основной характер, поскольку обращена не к причинам совершения преступления, а лишь к механизмам регуляции преступных действий.

Кроме того, она имеет существенные ограничения в применении, к примеру, к преступлениям, совершённым в состоянии сильного душевного волнения, в силу патологических проявлений характера или дефекта воли. В то же время она может быть полезна в объяснении преступлений, совершаемых посредством действий, требующих планирования, моделирования и контроля. В их отношении она может раскрыть внутренний контекст обоснования преступником своих действий, объяснять причины осуществления преступного замысла либо отказа от него.

В отечественной психологической науке к основаниям данного подхода можно отнести теорию осознанной саморегуляции поведения (О. А. Конопкин, В. И. Моросанова), которая описывает процессы управления поведением личностью через создание внутреннего плана действий, его преобразование и контроль [6]. В исследованиях различных видов социального поведения положения данной теории получили эмпирическую поддержку. Следуя её положениям, управление поведением опирается на конструирование представлений, применяемых личностью для моделирования своей деятельности, построения её плана, контроля и регуляции действий. Содержание данных представлений формируется путём осознания ситуации действия, возможностей и ограничений в социальном взаимодействии. М. И. Бобневой и Е. В. Шороховой описываются внутриличностные компоненты, участвующие в регуляции социального поведения - самосознание, самооценка, мотивационная система. Их роль заключается в формировании идеалов, убеждений, нормативных представлений и нравственных образований, с которыми личность соотносит планы своего поведения [2]. В концепции «раци- онального выбора» M. Bolger и J. Eck представление также рассматривается в качестве составляющей механизма принятия решения личностью. Как показывают их исследования, представления личности, подталкивающие к совершению преступления, иррациональны, поскольку не учитывают возможных социальных последствий - уголовного преследования, репутационных потерь и пр. [7].

В рамках теории «криминального мышления» [8] корыстным преступникам свойственны схожие стили мышления. Они считают свое криминальное поведение оправданным вследствие острой необходимости (например, «никак иначе нельзя»), популярности криминальных действий в обществе («все воруют»), провоцирующем или чрезмерно беспечном поведении жертвы («сам виноват»). Соглашаясь с С. Е. Борисовой, подчеркнём, что данные представления не только отражают осознание корыстного действия преступником, но в целом описывают его внутренний мир [2]. В исследованиях отечественных криминологов демонстрируется, что представления позволяют преступнику самооправдаться, снизить чувство вины [4], подготавливают его к преступлению, помогая быть более убедительным ${ }^{1}$.

Подводя итоги, отметим, что в отечественной и зарубежной криминальной психологии сформировалось целостное и непротиворечивое мнение относительно роли представлений в регуляции преступного поведения.

Представления участвуют в принятии решения о допустимости преступления, позволяют преступнику обосновать необходимость преступления себе и окружающим. Поэтому с практической точки зрения изучение представлений, регулирующих социальное поведение, позволяет оценить риск преступных действий. Ранее выполненный нами обзор методик исследования криминального мышления [5] позволяет сделать вывод, что многие из них измеряют представление о вероятности подвергнуться наказанию, быть пойманным и изобличенным. Данное представление используется в качестве индикатора прогноза рецидивных преступлений [12]. Ещё одним часто измеряемым представлением преступников выступает

${ }^{1}$ Онищенко О. Р. Манипулирование сознанием и поведением жертв при мошенничестве : автореф. дис. ... канд. психол. наук : 19.00 .06 : Онищенко Ольга Романовна. - Рязань, 2005. - 25 c. 
обесценивание жертв преступлений. В сознании преступника жертвы дегуманизируются, а их поведение оправдывает совершённое с ними преступление. Наконец, многие методики, измеряющие «стиль криминального мышления», оценивают гедонистическое представление преступников о лёгком и беспечном стиле жизни [9]. Суть его в том, что материальное благополучие и высокий социальный статус являются первичной ценностью в жизни, их достижение не требует труда и усилий, а зависит от удачи и везения. Описанные представления о безнаказанности, обесценивании жертвы преступлений и гедонистическом стиле жизни могут выступать регуляторами корыстного поведения, облегчая принятие решений о совершении преступления.

Для проверки данного предположения нами организовано эмпирическое исследование лиц, осуждённых за совершение коррупционных и корыстных преступлений, обладавших на момент преступления статусом сотрудника правоохранительных органов. Необходимость изучения данной категории лиц обусловлена, во-первых, задачей профилактики корыстной и коррупционной направленности у сотрудников правоохранительных органов, во-вторых, исследовательской задачей выступает операционализация и измерение уровня описанных представлений у лиц, осуждённых за совершение преступлений корыстной и коррупционной направленности.

\section{Процедура исследования}

Исследование осуществлялось в исправительном учреждении для бывших сотрудников правоохранительных органов. Базой для исследования стала исправительная колония общего режима №13 ГУФСИН по Свердловской области в г. Нижний Тагил. В колонии отбывают наказание бывшие сотрудники правоохранительных органов, осужденные за совершение различных видов преступлений. Исследование заключалось в индивидуальном анкетировании на вопросы специально разработанной анкеты. Участие в исследовании было добровольным.

Гипотезой исследования выступает предположение о различиях в представлениях между двумя категориями бывших сотрудников правоохранительных органов, совершивших корыстные преступления: а) в период прохождения службы в правоохранительных органах, б) в период трёх лет после увольнения со службы.
Предполагается, что по уровню представлений о безнаказанности, обесценивании жертвы преступления и гедонистической направленности лица из сопоставляемых нами групп могут различаться. Эти различия могут говорить о связности (единстве) представлений при условии подтверждения их взаимосвязи в группах. Данная гипотеза является дополнительной к основной и формулируется нами как предположение о различии во взаимосвязи между представлениями в сравниваемых выборках.

\section{Методы исследования}

1. Методом сбора данных выступает специально разработанная анкета, содержащая утверждения трёх видов - о безнаказанности преступного поведения, обесценивании жертвы преступлений и приемлемости гедонистической модели поведения. Все утверждения сопровождались шкалой из пяти градаций ответа («полностью не согласен - полностью согласен», с промежуточным ответом «не уверен»):

1) представление о безнаказанности преступлений изучалось пятью утверждениями (например, «Умные преступники избегают наказания», «Ловят преступников только из-за их неосмотрительности»).

Оценка согласованности утверждений проводилась методом расчёта $\alpha$-Кронбаха, дополненной оценкой корреляции между ними $(\mathrm{n}=211, \alpha$-Кронбаха $=0,76$, межпункт. корр. $=$ $0,65)$. Вследствие высокой согласованности и взаимосвязанности все ответы были обобщены в единый показатель «Убеждение в безнаказанности», описывающий субъективные представления осуждённых о возможности криминального поведения. Оценка распределения данного показателя показывает отклонение от нормального распределения $(\mathrm{M}=8,27, \mathrm{SD}=2,88, \mathrm{R}=$ 0-20, Shapiro-Wilk - p >0,1);

2) представление о жертве преступлений изучалось пятью утверждениями (например, «Потерпевшие всегда сами виноваты в произошедшем с ними», «Потерпевшие часто ведут себя хуже, чем преступники» и др.). Оценка согласованности показала удовлетворительные результаты ( $\mathrm{n}=211, \alpha$-Кронбаха $=0,77$, межпункт. корр. $=0,51)$. Полученные ответы также были обобщены в виде одного показателя «Обесценивание потерпевшего». Проведенная оценка распределения пока- 
зала, что его распределение отклоняется от нормального ( $\mathrm{M}=10,7, \mathrm{SD}=3,4, \mathrm{R}=0-20$, Shapiro-Wilk p > 0,1);

3) Рредставление о гедонистической модели поведения изучалось пятью утверждениями (например, «Для достижения успеха в жизни не нужно много работать», «Успех в жизни достигается проще, чем говорят окружающие» и др.). Проверка утверждений на согласованность показала удовлетворительные результаты ( $\mathrm{n}=211$, a-Кронбаха $=0,71$, межпункт. корр. =0,69). На этом основании все утверждения данной шкалы были обобщены до единого показателя, названного «Убеждение в гедонизме». Оценка распределения данного показателя показывает отклонение от нормального распределения $(\mathrm{M}=11,1$, $\mathrm{SD}=3,7, \mathrm{R}=0-20$, Shapiro-Wilk $\mathrm{p}>0,1)$.

Итак, в исследовании использовались три показателя: «Убеждение в безнаказанности», «Обесценивание потерпевшего», «Убеждение в гедонизме», обобщающие 15 высказываний с достаточной степенью согласованности и взаимосвязи. При этом они взаимосвязаны (R Спирмена $=0,73, \mathrm{n}=211$ ), что говорит об их непротиворечивости и соотнесённости друг с другом.

2. Методом подтверждения гипотезы выступила статистическая оценка различий в уровне данных представлений в группах лиц, осуждённых за совершение преступлений.

Вследствие несоответствия распределения переменных исследования закону нормального распределения нами применяется непараметрический аналог t-критерия Стьюдента Н-критерий Красскала-Уоллеса. Необходимость его применения, а не традиционного для такой задачи U-критерия Мана-Уитни обосновывается большим объёмом выборки (сопоставляются группы боле 100 человек). При этом Н-критерий ориентирован не на вычисление рангов, а оценивает разность медиан в сопоставляемых группах, что повышает его чувствительность к выборкам больших объёмов по сравнению с U-критерием.

\section{Выборка исследования}

Выборка исследования - бывшие сотрудники органов внутренних дел, отбывающие наказание в местах лишения свободы за совершение преступлений. Сопоставлялись две группы: совершившие преступления в период службы (в том числе в течение года после увольнения) - 105 человек и совершившие преступления в период более трёх лет после увольнения (106 че- ловек). Выборка гомогенная по полу (все мужчины) и возрасту.

\section{Результать исследования}

Изложение результатов проводится в соответствии с гипотезами.

1. Гипотеза о различии в представлениях между группами подтверждена. Сотрудники правоохранительных органов, совершившие преступления в период службы, статистически значимо различаются от бывших сотрудников по показателям «Убеждение в безнаказанности» (Нкрит. $(1, \mathrm{n}=210)=1,91 \mathrm{p}=0,05)$, «Обесценивание потерпевшего» (Нкрит. $(1, \mathrm{n}=210)=4,86$ $\mathrm{p}=0,02)$, «Убеждение в гедонизме» (Нкрит (1, $\mathrm{n}=210)=9,31 \mathrm{p}=0,002)$.

При этом группы статистически значимо различаются по медианному тесту - по показателю «Убеждение в безнаказанности» $-\chi 2=2,91$, $\mathrm{p}<0,06$, «Обесценивание потерпевшего» $-\chi^{2}=$ 7,33, $\mathrm{p}<0,001$, «Убеждение в гедонизме» $\chi^{2}=$ $3,98, \mathrm{p}<0,02$.

2. Гипотеза исследования о различии в связях показателей «Убеждение в безнаказанности», «Обесценивание потерпевшего», «Убеждение в гедонизме» в группах сотрудников подтверждена частично. Так, наиболее тесно связанными они являются в группе лиц, осуждённых за совершение преступлений корыстной направленности (напр. ст. 158 и 159, 160, 161, 163 УК РФ ( $\mathrm{n}=105, \mathrm{R}-$ Спирмена - 0,63, p < 0,01). В группах лиц, осуждённых за совершение преступлений коррупционной направленности (предусмотренных ст. 285, 286, 290 и 291 УК РФ), они связаны слабее ( $\mathrm{n}=106, \mathrm{R}-$ Спирмена - 0,46, $\mathrm{p}<0,01$ ).

\section{Обсуждение результатов}

Исследование основывается на теоретических представлениях о регуляции социального поведения представлениями личности и фокусируется на изучении субъективных представлений как регуляторов преступного поведения. Данное исследование изучает специфику представлений, свойственных корыстным преступникам в группах бывших сотрудников правоохранительных органов, осуждённых за совершение корыстных и коррупционных преступлений.

Результаты показывают, что в выборке лиц, осуждённых за корыстные и коррупционные преступления в период службы в правоохранительных органах, существуют представления, отражающие деградацию либо несформированность 
морально-нравственной сферы. Основанием для такого суждения выступает статистическое сравнение с группой бывших сотрудников, осуждённых за совершение аналогичных видов преступлений после увольнения из правоохранительных органов. Исследование выявило факт того, что мнение о безнаказанности преступлений, предпочтение гедонистического а не социально-значимого стиля поведения, а также обесценивание жертв преступлений сильнее выражены у лиц, преступивших закон в период прохождения службы в правоохранительных органах. Основываясь на данном выводе, можно выдвинуть предположение о необходимости дальнейшего исследования данных представлений и их роли в совершении коррупционных и корыстных преступлений.

Выявленные эмпирические факты свидетельствуют о том, что у лиц, осуждённых за совершение коррупционных преступлений, в отличие от лиц, осуждённых за совершение общеуголовных преступлений (без учёта специфики субъекта), представления о безнаказанности, гедонизме и обесценивании жертвы связаны слабее. Соответственно, у лиц, совершивших общеуголовные преступления, данные представления согласованы и взаимосвязаны друг с другом в большей степени.

Функциональное значение данных представлений может заключаться во влиянии на систему доводов при принятии решения о совершении преступления. Как и описывалось в теоретической части, в таком качестве они выполняют роль имплицитных аргументов в пользу преступления. Кроме того, полученные нами эмпирические сведения об их взаимосвязи позволяют сделать вывод о согласованности данных представлений. Соответственно, присутствие одного представления позволяет с определённой степенью уверенности говорить о наличии и других. Таким образом, данные представления в совокупности можно рассматривать в качестве системы аргументов для решения о совершении корыстного преступления. Эффект оказываемого ими воздействия заключается в искажении суждений о неизбежности наказания, ценности личности и человеческой жизни, ценности труда и порядка в обществе. Обратный эффект, как показывают C. Lloyd и R. Serin, может быть достигнут целенаправленным формированием у преступников противоположных по смыслу представлений [10].

В целом проведенное исследование пока- зывает, что тесная взаимосвязь представлений характерна только для общеуголовных преступлений, а для преступлений коррупционной направленности она является средней. Повидимому, степень согласованности изученных нами представлений в выборках неоднородна и варьируется в зависимости от специфики объекта и субъекта преступления. Этот факт открывает дальнейшие перспективы изучения представлений преступников как разновидности имплицитных регуляторов социального поведения.

Практическим результатом исследования выступает успешная операционализация представлений, сочетающихся с корыстными и коррупционными преступлениями. Перспективами исследования выступают, во-первых, дальнейшее совершенствование измерительного инструментария - повышение количества стимулов (пунктов), дальнейшая валидизация на выборках лиц, осуждённых за совершение корыстных общеуголовных преступлений. Без данной процедуры. психометрические характеристики использованного в исследовании набора утверждений так и не будут в полной мере оценены. Следует согласиться с критической оценкой G.Walter относительно низкой валидности опросников криминального мышления, валидизированных путём контрастного сопоставления осуждённых и правопослушных граждан [12]. Наиболее эффективной стратегией валидизации выступают продолжительные исследования представлений у лиц, начавших и прекративших свою криминальную «карьеру».

Выводы исследования могут использоваться для организации профессионального психологического отбора кандидатов на службу, а также выявления представлений о безнаказности, дегуманизациии и обесценивании, гедонистического стиля жизни как индикаторов риска корыстного поведения. Наконец, возможным применением результатов выступает психопрофилактическая работа с лицами, отбывающими наказание за совершение корыстных преступлений, по изменению данных представлений [11].

\section{Заключение.}

В статье обсуждались теоретические основания, процедура и результаты эмпирического исследования комплекса представлений, показавшего статистические различия в уровне выраженности у лиц, осуждённых за совершение 220 
корыстных и коррупционных преступлений в период прохождения службы в правоохранительных органах в отличие от лиц, совершивших данные преступления после завершения службы. Результаты подтверждают теоретиче- скую идею о роли представлений в регуляции социального поведения, расширяют её возможности в области предсказания преступного поведения.

\section{Список литературь}

1. Антонян Ю. М., Еникеев М. И., Эминов В. Е. Психология преступника и расследования преступлений. - Москва: Юристъ, 1996. - 336 с.

2. Бобнева М. И. Социальные нормы и регуляция поведения / Психологические проблемы социальной регуляции поведения / отв. ред. Е. В. Шорохова, М. И. Бобнева. - Москва: Наука, 1976. - C. 144-172.

3. Борисова С. Е. Психологические особенности лиц, совершивших мошенничество, и их учёт при расследовании преступлений // Прикладная юридическая психология. - 2008. - № 1. С. $108-113$.

4. Ефремова Г. Х., Ратинов А. Р. Правосознание и преступное поведение / Правосознание и правовое воспитание осуждённых : сборник научных трудов. - Москва: Изд-во Всесоюзного института по изучению причин и разработке мер предупреждения преступности, 1982. - С. 23 -33.

5. Злоказов К. В. Стили криминального мышления как диагностический конструкт // Вестник Уральского юридического института МВД России. - 2014. - № 1. - С. 76-80.

6. Моросанова В. И., Аронова Е. А. Саморегуляция и самосознание субъекта // Психологический журнал. - 2008. - Т.2. - № 1. - С.14-22.

7. Bolger M., Eck J. Situational Choice and Crime Events. // Journal of Contemporary Criminal Justice. - 2014. - № 31. - P. 12-29. - DOI: 10.1177/1043986214552605.

8. Jacoby J. E., Yochelson, S., Samenow, S. E. The Criminal Personality. - Vol. 1: Profile for Change // The Journal of Criminal Law and Criminology. - 1977. - № 68 (2). - 314 p. DOI: 10.2307/1142854

9. Knight K., Garner B., Simpson D., Morey J., Flynn P. An assessment of criminal thinking // Crime and Delinquency. - 2006. - № 52(91). - P. 159-177. - DOI: 10.1177/0011128705281749.

10. Lloyd C., Serin R. Agency and outcome expectancies for crime desistance: Measuring offenders' personal beliefs about change // Psychology, Crime, \& Law. - 2012. - № 18 (6). - P. 543-565. - DOI: 10.1080/1068316X.2010.511221.

11. Palmer E. J., Hollin C. R. Predicting reconviction using the Psychological Inventory of Criminal Thinking Styles with English prisoners // Legal and Criminological Psychology. - 2004. - № 9. - P. 57-68. - DOI: 10.1348/135532504322776852.

12. Walters $G$. The psychological inventory of criminal thinking styles: Part I: Reliability and preliminary validity // Criminal Justice and Behavior. - 1995. - № 22 (3). - P. 307- 325. - DOI: $10.1177 / 0093854895022003008$.

\section{References}

1. Antonyan Yu. M. Psikhologiya prestupnika i rassledovaniya prestupleniy / Antonyan Yu.M., Yenikeyev M.I., Eminov V.Ye. - Moskva: Yurist, 1996. - 336 c.

2. Bobneva M. I. Sotsial'nyye normy i regulyatsiya povedeniya // Psikhologicheskiye problemy sotsial'noy regulyatsii povedeniya / otv. red. Ye. V. Shorokhova, M. I. Bobneva. - Moskva: Nauka, 1976. S. 144-172

3. Borisova S. Ye. Psikhologicheskiye osobennosti lits, sovershivshikh moshennichestvo, i ikh uchet pri rassledovanii prestupleniy // Prikladnaya yuridicheskaya psikhologiya. - 2008. - № 1. - S. $108-113$.

4. Yefremova G. Kh., Ratinov A. R. Pravosoznaniye i prestupnoye povedeniye / Pravosoznaniye i pravovoye vospitaniye osuzhdennykh: sbornik nauchnykh trudov. - Moskva: Izd-vo Vsesoyuz. in-ta po izuch. prichin i razrab. mer preduprezhdeniya prestupnosti, 1982. - S. 23-33

5. Zlokazov K. V. Stili kriminal'nogo myshleniya kak diagnosticheskiy konstrukt // Vestnik Ural'skogo yuridicheskogo instituta MVD Rossii. - 2014. - № 1. - S. 76-80.

6. Morosanova V. I., Aronova Ye. A. Samoregulyatsiya i samosoznaniye sub»yekta // Psikhologicheskiy zhurnal. - 2008. - T.2. - №1. - C.14-22.

7. Bolger M., Eck J. Situational Choice and Crime Events. // Journal of Contemporary Criminal Justice. - 2014. - № 31. - P. 12-29. - DOI: 10.1177/1043986214552605. 
8. Jacoby J. E., Yochelson, S., Samenow, S. E. The Criminal Personality; Volume 1: Profile for Change. The Journal of Criminal Law and Criminology.- 1977. - № 68(2). - 314 p. - DOI:10.2307/1142854

9. Knight K., Garner B., Simpson D., Morey J., Flynn P. An assessment of criminal thinking // Crime and Delinquency. - 2006. - № 52(91). - P. 159-177. - DOI:10.1177/0011128705281749.

10. Lloyd C., Serin R. Agency and outcome expectancies for crime desistance: Measuring offenders' personal beliefs about change // Psychology, Crime, \& Law. - 2012. - № 18(6). - P. 543-565. - DOI: 10.1080/1068316X.2010.511221.

11. Palmer E. J., Hollin C. R. Predicting reconviction using the Psychological Inventory of Criminal Thinking Styles with English prisoners // Legal and Criminological Psychology. - 2004. - № 9. - P. 57-68. - DOI: 10.1348/135532504322776852.

12. Walters $G$. The psychological inventory of criminal thinking styles: Part I: Reliability and preliminary validity // Criminal Justice and Behavior. - 1995. - № 22(3). - P. 307- 325. - DOI: $10.1177 / 0093854895022003008$.

() Недилько М.С., Злоказов К.В., 2020

Статья поступила в редакцию 30.03.2020 г. 